\title{
Why we do it - the University of South Florida Tampa Library's commitment to open-access publishing
}

\author{
Todd A. CHAVEZ* \\ University of South Florida Library, 4202 E. Fowler Avenue, LIB 122, Tampa, FL 33620, USA
}

Received March 2009; accepted April 2009

Available online June 2009

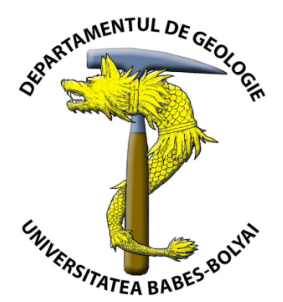

\begin{abstract}
The University of South Florida Tampa Library's support for open-access content is part of the organization's mission to advance scholarly communication generally and an important element of the Karst Information Portal initiative. As the costs associated with journal subscriptions increase and pressures to ensure unfettered access to high-quality, peer-reviewed research mount, research libraries must partner with scholars to establish sustainable open-access publishing models.
\end{abstract}

The University of South Florida Tampa Library is pleased to support publication of Studia Universitatis BabeşBolyai, Geologia. Our commitment to open-access publishing generally is borne of the academic library community's concern for improving access to quality information resources - access impeded by commercial models of publishing and rapidly escalating journal subscription costs. The Tampa Library views support for this and other open-access journals as a mechanism to fulfill our mission to advance scholarly communication and to begin to mitigate costs.

On the local level, our financial and logistical support is an integral component of a strategy to shift the library's undergraduate/basic graduate collection and service profile to one consistent with the institution's Carnegie Classification as a "Doctorate Granting Research University - Very High Research Activity." Additionally, this effort is an important element of the library's Karst Studies Collection initiative and the Karst Information Portal (http://www.karstportal.org).

The term open-access is defined by the Library of Congress as, "A publication model wherein neither readers nor a reader's institution are charged for access to articles or other resources. Users are free to read, download, copy, distribute, print, search, or link to the full texts of these articles. The only constraint on reproduction and distribution, and the only role for copyright ... should be to give authors control over the integrity of their work and the right to be properly acknowledged and cited" (Library of Congress, 2004).

Although information in the open-access environment is free of cost to individual and institutional consumers, openaccess publishing is not free of cost to the entity engaged in the publishing activity, in this case the USF Tampa Library.
Regardless of the costs involved, research libraries are "becoming more deeply engaged in the creation and dissemination of knowledge and are becoming essential collaborators with the other stakeholders in these activities" (Lougee, 2002). A natural outgrowth of this engagement is the research library's emergent role as publisher. This strategic direction compliments current strengths in commercial electronic collections, digital initiatives, and online services to end users and advances the library's goal of attaining membership in the Association of Research Libraries through direct linkage to the association's 2005 2009 strategic direction supporting barrier-free and sustainable models of scholarly communication (ARL, 2005).

In his 2002 presentation to the Drake University community, SPARC Enterprise Director Rick Johnson described his conception of a "Circle of Gifts" - a circle uniting the producers and consumers of content with the wider society and the research library. Open-access publishing actuates the library's role in this endeavor, in the process benefiting each stakeholder through cost-effective management and facilitation of scholarly communication. Vitek Tracz, chairman of the Science Navigation Group and founder of BioMed Central states the ethical case succinctly: "since OA is plainly beneficial to society 'there is an ethical reason for insisting that it happens"” (Tracz, 2006).

Journal costs, regardless of format, are escalating and the Tampa Library's decision to engage in open-access journal publishing is in part a deliberate response to the increasing cost of scholarly communication as measured in a variety of dimensions including costs of technology, distribution, materials, and reacquisition of copyright permissions.

In 2000, the STM publishing market was valued at $\$ 9.5$ billion, including $\$ 1.6$ billion in aggregator content, with 68 
percent of the total generated by commercial vendors and 32 percent contributed by non-profit entities. This division is important when the nature and values of the commercial and scholarly publishing "cultures" are considered. At the risk of over-generalizing the context, scholarly publishing cultures attempt to increase awareness of the content, focus efforts on publication output, and reward prestige, promotion, and tenure. By contrast, commercial publishing cultures maximize product value, focus efforts on controlling content and access to same, and reward increased profit (Johnson, 2002). These are clearly divergent views of the publishing endeavor.

The net result of these trends is a gradual pressure on both the ability of scholars and researchers to communicate with one another and for consumers of the intellectual energies of the research community to access the information thus generated. As the research library assumes the role of publisher, the intellectual property of the community of scholars supported by the library remains with the academy and available for dissemination via an open-access model.

In 2006, a group of 29 scientists, information specialists, and policy makers from 18 organizations met in Carlsbad, New Mexico to plan for the development of a Karst Information Portal (KIP), a project to create cost-free open access to quality information resources to advance karst, cave, and aquifer research.

The workshop was organized by the National Cave and Karst Research Institute, the University of New Mexico University, and the University of South Florida. A variety of organizations were represented including the Los Alamos National Laboratories, the National Park Service, the United States Geological Survey, the Karst Waters Institute, ESRI, and the Bureau of Land Management. International participants included representatives of the UIS Informatics Commission and the Karst Research Institute of Slovenia. Developers of two NSF-funded portals, the GEON (http://www.geongrid.org/index.php) and CHRONOS (http://www.chronos.org/) projects also participated in the workshop.

KIP officially launched in June 2006 with a basic catalog of speleological literature, a clearinghouse of links to quality information resources for karst researchers, and an infrastructure designed to host future content including journals and other digital publications. At present KIP hosts a digital archive of the NSS News and publications of the Association of Mexican Cave Studies. Plans to expand retrospective collections for several key publications in karst studies are in various stages of realization. In 2009, the USF Tampa Library digitally published Cave Minerals of San Salvador Island, Bahamas, the first monograph in the "University of South Florida Karst Studies Series" - a series that will be freely accessible to the research community.

Our experience with the Karst Information Portal project catalyzed the library to publish open-access journals in several interdisciplinary and globally relevant domains beyond the geosciences including globalization, urban planning, educational policy analysis, and quantitative literacy. We believe that our contributions facilitate the activities of researchers worldwide from many disciplines who are pursuing open-access models of scholarly communication as a means of maximizing access to their intellectual energies (Berlin, 2003; Willinsky, 2006).
The many modes of digital publishing and the Internet's power through flexibility offer numerous opportunities for scholars to expand access to their work while preserving the time-honored traditions of peer-review. Studia Universitatis Babes-Bolyai, Geologia is a clear example of the benefits realized when libraries and scholars unite to address the ethical and financial challenges and create access to highquality, peer-reviewed research.

\section{$R$ e f e r e n c e s}

Association of Research Libraries, ARL Strategic Plan, 2005-2009. (accessed February 2, 2007). http://www.arl.org/arl/governance/stratplan.shtml.

"Berlin Declaration on Open Access to Knowledge in the Sciences and Humanities." Conference on Open Access to Knowledge in the Sciences and Humanities, 20 - 22 October 2003, Berlin. http://oa.mpg.de/openaccessberlin/berlin_declaration.pdf (accessed July 15, 2007).

Johnson, R. Igniting Change in Scholarly Communication, Paper presented at the Cowles Library National Advisory Board Guest Lecture, Drake University, Des Moines, Iowa, October 4, 2002.

Library of Congress, Summit of Serials in the Digital Environment: Glossary. CONSER: Cooperative Online Serials. http://www.loc.gov/acq/conser/glossary.html (accessed July 15, 2007).

Lougee, W.P. 2002, Diffuse Libraries: Emergent Roles for the Research Library in the Digital Age. Washington, DC, www.clir.org/pubs/reports/pub108/pub108.pdf.

Tracz, V. Interview with Richard Poynder: Open and Shut? Building the Business Model. http://poynder.blogspot. com/2006/05/interview-with-vitek-tracz.html (accessed May 23, 2006).

Willinsky, J. 2006, The Access Principle: The Case for Open Access to Research and Scholarship. Cambridge, MA, Massachusetts Institute of Technology, 287 p. 